\title{
MALARIA MORBIDITY AMONG SCHOOL CHILDREN LIVING IN TWO AREAS OF CONTRASTING TRANSMISSION IN WESTERN KENYA
}

\author{
SIÂN E. CLARKE, SIMON BROOKER, JOSEPH KIAMBO NJAGI, ELIUD NJAU, BENSON ESTAMBALE,
} ERIC MUCHIRI, AND PASCAL MAGNUSSEN

Department of Infectious and Tropical Diseases, London School of Hygiene and Tropical Medicine, London, United Kingdom; Malaria Control Division, and Division of Vector Borne Disease, Ministry of Health, Nairobi, Kenya; Institute for Infectious and Tropical Diseases, University Of Nairobi, Nairobi, Kenya; Danish Bilharziasis Laboratory, Charlottenlund, Denmark

\begin{abstract}
Research in malaria-endemic areas is usually focused on malaria during early childhood. Less is known about malaria among older school age children. The incidence of clinical attacks of malaria was monitored, using active case detection in primary schools, in two areas of western Kenya that differ in the intensity of transmission. Clinical malaria was more common in schools in the Nandi highlands, with a six-fold higher incidence of malaria attacks during the malaria epidemic in 2002, compared with school children living in a holoendemic area with intense perennial transmission during the same period. The high incidence coupled with the high parasite densities among cases is compatible with a low level of protective immunity in the highlands. The malaria incidence among school children exposed to intense year-round transmission (26 per 100 school children per year) was consistent with reports from other holoendemic areas. Taken together with other published studies, the data suggest that malaria morbidity among school age children increases as transmission intensity decreases. The implications for malaria control are discussed.
\end{abstract}

\section{INTRODUCTION}

In areas of intense transmission, children gradually acquire immunity that protects them from severe malaria attack and death. ${ }^{1}$ The bulk of malaria morbidity and mortality is thus concentrated in pre-school age children, and most research has naturally focused on this high-risk group. Little is known about malaria among older children, despite the potential impact malaria can have on school performance and educational attainment. ${ }^{2,3}$ Schools offer a potential delivery mechanism for interventions, but data are lacking to determine whether the burden of malaria among school children is sufficient to warrant investment. ${ }^{4}$ Epidemiologic and ethnographic studies carried out in western Kenya in 2002 sought to address this gap.

The age-specific pattern of malaria morbidity and mortality reflects cumulative exposure, with populations subject to more intense transmission acquiring immunity at an earlier age. ${ }^{1,5}$ Malaria incidence studies were therefore carried out in two areas that differ in the intensity of transmission: a highland area with low and unstable transmission and a holoendemic area with intense year-round transmission.

\section{MATERIALS AND METHODS}

Malaria case surveillance was carried out among school children in two areas of western Kenya, located at differing altitudes within the same river system (Figure 1). Both areas experience a bimodal rainfall pattern with the heaviest rainfall typically occurring in March-May, with a smaller peak in November-December. Most malaria is caused by Plasmodium falciparum, and Anopheles gambiae s.s. is the principal vector in both areas. ${ }^{6}$

Holoendemic study area. The first group of schools was located in Bondo District, a hot and relatively dry area on the shores of Lake Victoria, lying at an altitude of 1,219-1,230 meters. Rainfall typically ranges between 750 and $1,000 \mathrm{~mm}$ per year, and temperature ranges between $14^{\circ} \mathrm{C}$ and $30^{\circ} \mathrm{C}$. Continuous precipitation supports intense year-round transmission, with two seasonal peaks in malaria cases reflecting the bimodal rainfall pattern. The entomologic inoculation rate varies between 60 and 300 infective bites per year. ${ }^{7}$ The population is mainly of the Luo ethnic group, and is engaged in subsistence agriculture and fishing. The incidence of malaria was monitored in four schools near Bondo Town $\left(0.08^{\circ} \mathrm{S}\right.$, $34.23^{\circ} \mathrm{E}$ ): Bar Konwino, Nyawita, Uloma, and Nyakasumbi. Three of the schools were located in rural settings with a subsistence economy, and one (Nyakasumbi) was in a more peri-urban area on the edge of Bondo Town. The main health facility serving the study population was Bondo District Hospital.

Low endemic highland study area. The second group of schools was located in Nandi District in the cooler and wetter Kenyan highlands, which experiences low and unstable seasonal transmission. Rainfall averages $2,428 \mathrm{~mm}$ per year. Average minimum and maximum temperatures are $12.2^{\circ} \mathrm{C}$ and $23.6^{\circ} \mathrm{C}$ (Kaimosi tea estate meteorologic station adjacent to the schools, unpublished data). Malaria transmission is acutely seasonal with most cases occurring during May-July after the peak rainfall, although the extent of the malaria burden varies considerably year to year. ${ }^{8}$ The area is prone to epidemics, with the most recent epidemic occurring in JuneJuly 2002, during the period of this study. ${ }^{9}$

The population of the area consists of indigenous Kalenjin people and Luhya settlers who have come from the lower malaria-endemic parts of western Kenya during the past 30 years. The economy is primarily rural subsistence agriculture, with some families growing tea as a cash crop. Other economic opportunities include casual labor on local tea estates. Schools within the catchment area of the Kapkangani Government Health Center $\left(0.19^{\circ} \mathrm{N}, 34.98^{\circ} \mathrm{E}\right)$ were identified and classified according to ethnic mix. To minimize the effect of differential immunity, host genetic heterogeneity, and/or travel to malaria-endemic areas on the risk of malaria, only schools where almost all pupils were of indigenous Kalenjin descent were eligible for inclusion in the study. The three schools closest to the health center that fulfilled the ethnicity criteria were selected. These schools were located on the Nandi Escarpment and the elevation of the pupils' homes varied considerably within schools. The altitude range of each school's catchment population was similar, but was greatest for Kiborgok school (range $=1,681-2,056$ meters), where 


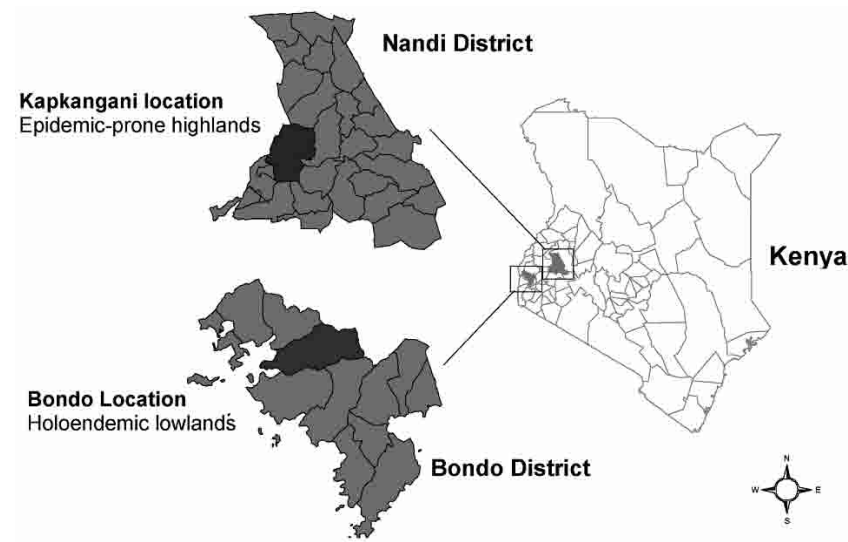

FIGURE 1. Map of Kenya showing the location of the study areas.

some pupils lived at higher elevations than those attending Koibem or Kabaskei school, and where the elevation of pupil's homes ranged between 1,713 and 1,885 meters and 1,739 and 1,830 meters, respectively.

Malaria surveillance. The incidence of malaria among children in standards 3-7 (typically 8-14 years old) was monitored prospectively over an 11-week period in May-July 2002, which corresponded to the time of peak malaria transmission in both study areas. A series of meetings were held with teachers, parents, and community leaders to explain the purpose and methodology of the study, that participation was voluntary, and that children were able to withdraw from the study at any time. Written parental consent was obtained for all children prior to enrollment. Three children were not enrolled due to parental refusal. Ethical approval was obtained from the Ethical Review Board of Kenyatta National Hospital, Nairobi and the Danish Central Ethical Committee.

Data were collected through a system of active case detection at the seven schools, supplemented by continuous passive case detection at the local government health unit. Each school was visited by the surveillance team (nurse, laboratory technician, and field assistant) 2-3 times per week to identify children with clinical episodes of malaria. To maximize case detection, class teachers identified and recorded the names of any children who were ill or absent from school each morning. Any child reporting fever or other malaria-related symptoms, or absenteeism due to illness was notified to the surveillance team for follow-up and screening either in school or at home. Absentees were visited at home. A morbidity questionnaire was completed and included age, sex, history and duration of fever, other presenting signs and symptoms, and whether the child had taken antimalarials in the previous week. A finger prick blood sample was taken from children who satisfied the following screening criteria: 1) one or more of the following symptoms suggestive of malaria within the previous 24 hours: fever, chills/shivering, rigors, vomiting, malaise, or generalized body pain, or 2) a demonstrable axillary temperature $\geq 37.5^{\circ} \mathrm{C}$. Giemsa-stained thick and thin blood films were prepared and the number of asexual parasites counted against 200 leukocytes and expressed as parasites/microliter, assuming a white blood cell count of $8,000 / \mu \mathrm{L}$. Hemoglobin levels were measured using a portable HemoCue photometer (HemoCue, Angelhom, Sweden). School children with clinically diagnosed episodes were treated with a standard dose of sulfadoxine-pyrimethamine on the day of survey. Other conditions requiring treatment were referred to the health unit.

The active surveillance in schools was supplemented by continuous passive case surveillance at Kapkangani Health Center and Bondo District Hospital. To minimize obstacles to seeking treatment, diagnosis and treatment at the local health unit were provided free of charge for school children enrolled in the study. At the end of the surveillance period, a crosssectional survey among all school children was conducted to assess anthropometric status and the prevalence of helminth infections. Stool samples were examined for Schistosoma mansoni and intestinal nematodes using the Kato-Katz method. Weight was measured to the nearest $0.1 \mathrm{~kg}$ on a Soehnle electronic balance (Leicester, United Kingdom) with children wearing minimum clothing. Height was measured to the nearest $0.1 \mathrm{~cm}$ using a portable fixed-base stadiometer. Age was derived from the date of birth recorded in the school register. Height-for-age and weight-for-age of each child were expressed as differences from the median National Center for Health Statistics (NCHS) (Hyattsville, MD) reference values in $z$-scores. ${ }^{10} \mathrm{~A}$ child was classified as stunted or underweight if his or her z-score of height-for-age and weight-for-age, respectively, was in excess of 2 SD below the NCHS median.

Household mapping and household surveys in the highlands. Since some heterogeneity in transmission risk was anticipated within the highland study area, the homes of every schoolchild who had been enrolled in the study were visited and mapped. ${ }^{11}$ The location and elevation of homes were determined using a hand-held differential global positioning system with a positional and vertical accuracy within five meters.

Statistical analysis. Person-years analysis was carried out to determine the incidence density of episodes of clinical attacks. An episode of malaria was defined as a child with one or more of the screening symptoms and a parasite density threshold $\geq 500$ parasites $/ \mu \mathrm{L}$ of blood, which was previously shown to be appropriate for children 10-14 years old in a holoendemic area of western Kenya. ${ }^{12}$ Episodes in the same child occurring more than 28 days apart were regarded as repeat attacks. Four episodes, that occurred between 21 and 28 days after the first episode, were classified as late treatment failures and excluded from analysis.

For each child, the period under surveillance was determined from the class register of attendance kept by teachers. Any child absent from school for a period of 10 or more consecutive days was censored during the period of absence. Similarly, any child known to have received medical attention from any source other than the survey team, including any public or private health care provider, was censored for a period of 28 days ( 31 children in Nandi and 4 in Bondo). Twelve children, eight who were persistently absent and four who were treated privately on more than one occasion, were removed from the dataset.

The standard World Health Organization cut-off value of $120 \mathrm{~g} / \mathrm{L}$ for defining anemia in children 12-14 years old was corrected for the lower mean hemoglobin seen in populations of African extraction $(-10 \mathrm{~g} / \mathrm{L})$ and height above sea level. ${ }^{13}$ Due to the altitude difference, anemia was defined differently in the two study areas: a cut-off of $112 \mathrm{~g} / \mathrm{L}$ was applied in Bondo and a cut-off of $116 \mathrm{~g} / \mathrm{L}$ was applied in Nandi. No 
adjustment was made for variation with age and sex. Data were analyzed using Epi-Info version 6.04d (Centers for Disease Control and Prevention, Atlanta, GA) and Excel ${ }^{\circledR} 2002$ (SP1) (Microsoft, Redmond, WA). A chi-square test or Fisher's exact test (as appropriate) were used to assess differences in proportions. Continuous data were analyzed using Student's $t$-test. A logarithmic transformation was applied to normalize parasite counts, and the geometric mean parasite density was compared. Incidence rates were compared using a trend test for rates. ${ }^{14}$

\section{RESULTS}

Data from 1,239 children in standards 3-7 were analyzed: 523 children in Bondo and 716 in Nandi. The age and sex distribution was similar in both districts (Table 1). A greater proportion of children in Nandi were underweight for their age, although this may reflect differences in physique between the two ethnic groups rather than nutrition. Helminth infections were uncommon in both areas, nevertheless the prevalence of all intestinal helminth species was higher in Bondo than in Nandi. Bed net use was low, although more school children reported sleeping under a bed net in Bondo than in Nandi. Recent use of an antimalarial was reported by $<10 \%$ of the school children, and was more frequent in Bondo than in Nandi.

During the 11-week surveillance period, 606 school children with suspected malaria were screened: 330 children in Nandi and 276 in Bondo. The proportion of symptomatic children with confirmed parasitemia (any Plasmodium species) differed according to study area, with more children being slide positive in Nandi (47\%) than in Bondo $(23 \%)$. The number of children with a parasite density $\geq 500$ parasites $/ \mu \mathrm{L}$, indicating a high probability that their symptoms are attributable to malaria infection was 146 (44\% of those screened) in Nandi and 38 (14\%) in Bondo. Hemoglobin levels were higher in Nandi than in Bondo (Mean hemoglobin level $=130 \mathrm{~g} / \mathrm{L}$ and $122 \mathrm{~g} / \mathrm{L}$, respectively; $t=5.78, P<0.001)$, which was slightly in excess of the $4-5 \mathrm{~g} / \mathrm{L}$ difference that would be expected due to the differing altitude between the two areas. Similarly, the proportion of school children classified as anemic was slightly higher in Bondo than in Nandi:
$25 \%$ of the 255 children in Bondo whose hemoglobin was assessed had a hemoglobin level < $112 \mathrm{~g} / \mathrm{L}$ compared with $19 \%$ of 298 children in Nandi with a hemoglobin concentration $<116 \mathrm{~g} / \mathrm{L}$. This difference was not statistically significant $\left(\chi^{2}=3.22, P=0.073\right)$.

Signs and symptoms. The most common symptoms reported by the 184 school children with a clinical attack of malaria (as defined earlier) in the 24 hours before examination were headache $(88 \%)$, chills $(31 \%)$, fever $(17 \%)$, malaise/body weakness $(14 \%)$, vomiting $(11 \%)$, generalized body pain $(11 \%)$, abdominal pain $(11 \%)$, and cough $(7 \%)$. In contrast to the low rate of self-reported fever, more than half the children were febrile on the day of screening (54\% with an axillary temperature $\geq 37.5^{\circ} \mathrm{C}$ ), indicating that fever is not readily perceived by school children. Twenty-two percent of the cases were anemic, and one case had a hemoglobin level $<70 \mathrm{~g} / \mathrm{L}$. None of the cases died.

A raised body temperature was the most useful diagnostic indicator in both study areas, with a greater proportion of cases being febrile than non-cases (Table 2). Cases in Nandi were also more likely to report chills and/or vomiting in the last 24 hours, but these were non-specific signs in Bondo. Headache, malaise, and abdominal pain were as commonly reported among cases as among non-cases in both areas. Malaria was more clearly associated with anemia in Nandi, with the mean hemoglobin level being significantly lower among cases than among non-cases, and with $23 \%$ of the cases being anemic compared with $16 \%$ of the non-cases. The mean hemoglobin level did not differ between cases and non-cases in Bondo.

Incidence of clinical attacks of malaria. One-fourth of the school children under surveillance in the highland schools experienced one or more clinical attacks, with $11(2.1 \%)$ experiencing two attacks within the 11-week surveillance period. No repeat attacks were seen in lowland schools. The incidence of malaria was much higher in highland schools than in the lowland schools (Figure 2). The overall incidence of clinical attacks in Nandi schools was $0.029 /$ child-week of observation $(95 \%$ confidence interval $[\mathrm{CI}]=0.024-0.034)$ compared with $0.005 /$ child-week (95\% CI $=0.003-0.006)$ in Bondo schools $\left(\chi^{2}=116.79\right.$, degrees of freedom $[\mathrm{df}]=1$, $P<0.001)$. If all children with a positive blood film are clas-

TABLE 1

Characteristics of school children under surveillance (standards 3-7 [8-14 years old])*

\begin{tabular}{|c|c|c|c|}
\hline & Bondo & Nandi & $P$ \\
\hline Malaria endemicity & Holoendemic perennial & Low and unstable & \\
\hline Altitude (meters) & $1,219-1,230$ & $1,681-2,056$ & \\
\hline Number enrolled & 720 & 520 & \\
\hline Mean age in years (range) & $12.1(8-17)$ & $12.6(7-20)$ & \\
\hline Sex ratio, $\%$ male & $48.8 \%$ & $49.1 \%$ & NS \\
\hline \multicolumn{4}{|l|}{ Anthropometric status } \\
\hline Stunted & $17.5 \%$ & $19.4 \%$ & NS \\
\hline Underweight & $9.5 \%$ & $24.6 \%$ & $<0.001$ \\
\hline \multicolumn{4}{|l|}{ Helminth prevalence } \\
\hline Ascaris lumbricoides & $17.0 \%$ & $14.5 \%$ & NS \\
\hline Trichuris trichiura & $17.4 \%$ & $7.3 \%$ & $<0.001$ \\
\hline Hookworm & $24.9 \%$ & $12.2 \%$ & $<0.001$ \\
\hline Schistosoma mansoni & $11.8 \%$ & $0.0 \%$ & $<0.001$ \\
\hline Bed net use (yes/no) & $11.5 \%$ & $2.4 \%$ & $<0.001$ \\
\hline Use of antimalarials in previous week & $8.3 \%$ & $3.9 \%$ & 0.023 \\
\hline
\end{tabular}


TABLE 2

Clinical presentation of school children with suspected malaria*

\begin{tabular}{|c|c|c|c|c|c|c|}
\hline & \multicolumn{3}{|c|}{$\begin{array}{c}\text { Bondo } \\
\text { Holoendemic schools }\end{array}$} & \multicolumn{3}{|c|}{$\begin{array}{c}\text { Nandi } \\
\text { Highland schools }\end{array}$} \\
\hline & $\begin{array}{c}\text { Slide negative or } \\
\text { parasitemia }<500 / \mu \mathrm{L}\end{array}$ & $\begin{array}{c}\text { Malaria cases } \\
\geq \leq 500 / \mu \mathrm{L}\end{array}$ & $P$ & $\begin{array}{c}\text { Slide negative or } \\
\text { parasitemia }<500 / \mu \mathrm{L}\end{array}$ & $\begin{array}{l}\text { Malaria cases } \\
\geq 500 / \mu \mathrm{L}\end{array}$ & $P$ \\
\hline Number of children & 238 & 38 & & 184 & 146 & \\
\hline \multicolumn{7}{|l|}{ Self-reported symptoms } \\
\hline Fever in last 24 hours & $4 \%$ & $5 \%$ & NS & $13 \%$ & $20 \%$ & 0.07 \\
\hline Chills/shivering & $32 \%$ & $21 \%$ & NS & $19 \%$ & $34 \%$ & 0.002 \\
\hline Headache & $87 \%$ & $79 \%$ & NS & $85 \%$ & $90 \%$ & NS \\
\hline Malaise/body weakness & $7 \%$ & $5 \%$ & NS & $15 \%$ & $16 \%$ & NS \\
\hline Generalized body pain & $1 \%$ & $5 \%$ & NS & $7 \%$ & $12 \%$ & 0.07 \\
\hline Abdominal pain & $11 \%$ & $13 \%$ & NS & $14 \%$ & $11 \%$ & NS \\
\hline Vomiting & $3 \%$ & $8 \%$ & NS & $2 \%$ & $12 \%$ & $<0.001$ \\
\hline Febrile $\left(\geq 37.5^{\circ} \mathrm{C}\right)$ & $14 \%$ & $31 \%$ & 0.010 & $27 \%$ & $60 \%$ & $<0.001$ \\
\hline Mean hemoglobin level & $122 \mathrm{~g} / \mathrm{L}$ & $121 \mathrm{~g} / \mathrm{L}$ & NS & $133 \mathrm{~g} / \mathrm{L}$ & $128 \mathrm{~g} / \mathrm{L}$ & 0.007 \\
\hline Anemic & $26 \%$ & $19 \%$ & NS & $16 \%$ & $23 \%$ & 0.096 \\
\hline
\end{tabular}

sified as a malaria case, the incidence seen in Nandi increases slightly to 0.031 clinical attacks/child-week. This pattern was mirrored in the parasite density among slide-positive children (Figure 3). Infected school children in the highlands had high parasite loads (geometric mean $=9,154$ parasites $/ \mu L$ ). In contrast, parasite levels among slide-positive school children in Bondo were much lower (geometric mean $=739 / \mu \mathrm{L} ; t=$ 10.52, $P<0.001)$.

Incidence estimates for the individual schools in Bondo were similar, ranging from 0.0009 to 0.0069 clinical attacks/ child-week of observation $(P>0.05)$. However in the highlands, there was greater heterogeneity between schools in the same area (Figure 2). The overall incidence was lower in Kiborgok (0.013 clinical attacks/child-week), whose catchment population included homes located higher up the Nandi escarpment, than for the other two schools (0.032 and 0.047 clinical attacks/child-week, respectively). When incidence is calculated according to the elevation of each child's home, a steady decrease is seen with increasing altitude $\left(\chi^{2}\right.$ for trend $=30.87, \mathrm{df}=1, P<0.001$ ) (Figure 4$)$. A five-fold difference in the incidence of clinical malaria was observed among highland school children sleeping in houses located at an altitude $<1,750$ meters compared with those living at an altitude $\geq 1,850$ meters: 0.009 compared with 0.048 clinical attacks/

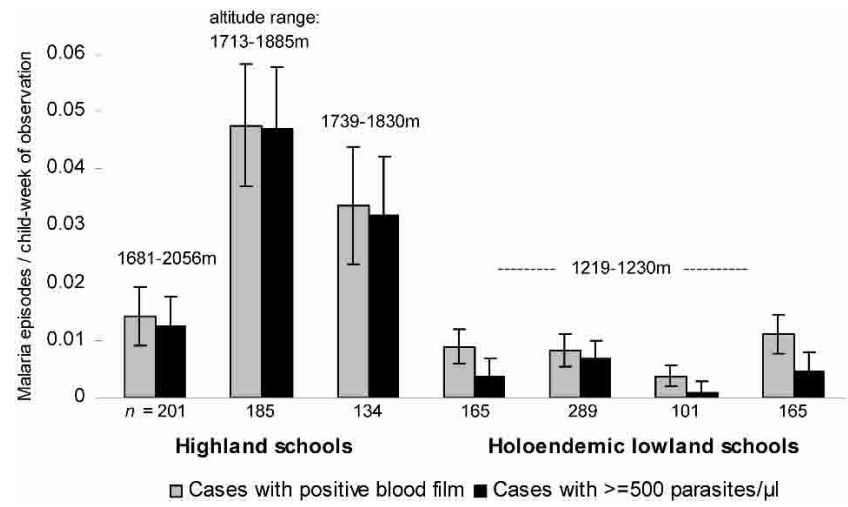

FIGURE 2. Incidence of clinical malaria among school children living in two areas of western Kenya: an epidemic-prone highland area and a holoendemic area of intense, perennial transmission. Error bars show $95 \%$ confidence intervals. $\mathrm{m}=$ meters. child-week, respectively (relative risk $=5.1,95 \% \mathrm{CI}=2.5$ 10.2).

The incidence decreased among older children in both districts, but these age trends were not significant. There were no differences according to sex.

\section{DISCUSSION}

People living in areas where malaria transmission is low and unstable remain at risk of clinical attacks of malaria at older ages, and epidemics can result in increased morbidity among school children, more deaths, and considerable disruption of schoolwork. ${ }^{15} \mathrm{~A}$ six-fold higher incidence of malaria attacks was seen among school children during the epidemic in the Kenyan highlands in 2002, compared with school children living in a holoendemic area of western Kenya, during the period of peak transmission in both areas. The high incidence rate, coupled with high parasite densities among cases, is compatible with a low level of functional immunity in the highlands. The majority of children were of indigenous highland descent, and data on history of residence showed that

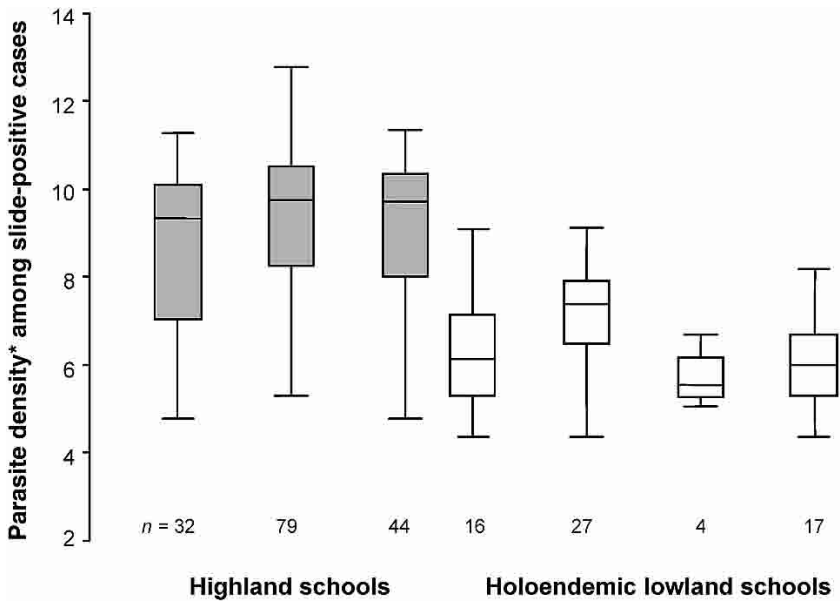

Figure 3. Plasmodium parasite density among symptomatic cases with a positive blood film $(\mathrm{n}=219)$. *The data are logtransformed using a natural logarithm: $\ln$ (parasite count). Horizontal lines in boxplots show $2 \frac{1}{2}, 25,50$ (median), 75, and 971/2 percentile points. 


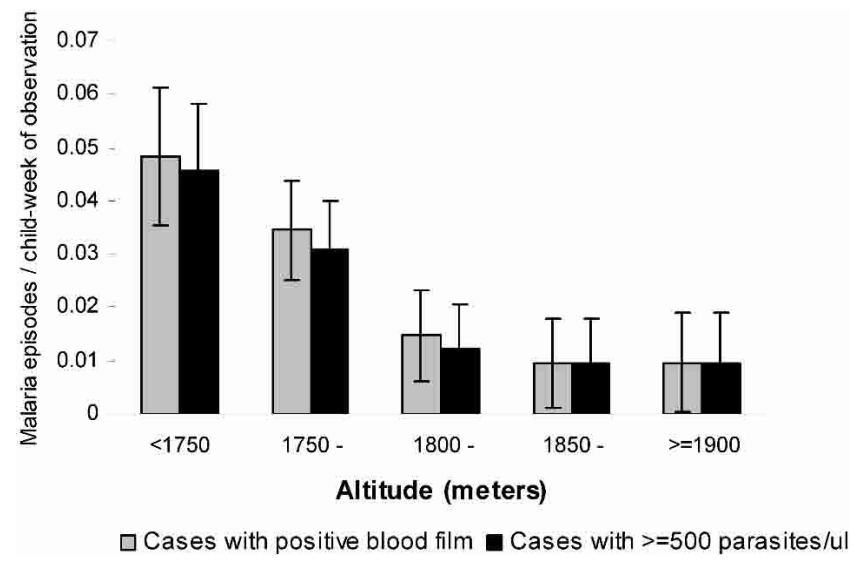

FIGURE 4. Incidence of clinical malaria among school children in the highlands in relation to the altitude of the child's home: altitude range $=1,681-2,056$ meters. Error bars show $95 \%$ confidence intervals.

none had previously lived in a malarious area. With the increasing frequency of epidemics in the east African highlands, ${ }^{8}$ the impact that malaria may have on children and their educational achievement in school should not be overlooked.

In contrast, the lower incidence of malaria in the holoendemic lowland schools is compatible with repeated exposure to malaria parasites in early life leading ultimately to the ability to limit parasite growth, such that by the time a child starts school, episodes of clinical malaria have usually become both less common and less severe. We cannot exclude the possibility that genetic differences between the two populations also play a role because this was not examined in the study. Prior use of antimalarials could affect both observed disease incidence and parasite density, but although more children in holoendemic schools reported having taken an antimalarial drug prior to screening compared with children in highland schools, this is not sufficient to account for a six-fold difference in incidence. It is also questionable whether the drugs and dose administered would be sufficient to achieve clinical cure. ${ }^{16}$ The case definition used incorporated a parasite density cut-off that was found to be appropriate among school children living in holoendemic areas, ${ }^{12}$ and may be less valid for a non-immune population in whom infection is more likely to result in symptomatic illness. However, in highland schools the estimates of incidence were similar irrespective of whether a parasite density cut-off was used or not, due to the high parasite densities seen in children with symptoms. It was thus possible to apply a single case definition for this age group, irrespective of local transmission intensity.

The patterns in hemoglobin level seen in the two study areas may in part reflect the differing pathologic mechanisms that give rise to anemia in parasitemic children. ${ }^{17}$ In Nandi, clinical attacks of malaria were clearly associated with lower hemoglobin levels, suggesting that uncontrolled parasite growth and increased erythrocyte destruction in a nonimmune subject results in acute anemia. The high parasite densities among cases support this. Increased erythrocyte destruction may continue up to two weeks post-infection, ${ }^{18}$ and the full extent of acute malaria-related anemia in the highlands may be underestimated in our dataset. In Bondo, parasite densities were lower and clinical episodes of malaria were not associated with reduced hemoglobin levels. Nonetheless, chronic, low-level, asymptomatic infection with malarial parasites may have contributed to decreased hemoglobin levels in this semi-immune population. Other environmental and genetic differences between the two study areas may also play a role, such as the higher prevalence of hookworm in Bondo than in Nandi.

Ethnographic investigations showed that local perceptions of malaria differed between highland and lowland schools, ${ }^{19}$ and were consistent with the differing epidemiology of malaria in the two areas. In the Nandi highlands, malaria was seen as a life-threatening illness, and all those interviewed knew of school children who had died of malaria. There was a distinct local term for malaria (cheptigonit) and specific local herbal medicines. In contrast, in Bondo, malaria was seen as a mild "everyday illness" that was not clearly distinguished from other common illnesses. Nevertheless, malaria was ranked as the most common health problem among school children in both areas.

The observed incidence of clinical attacks in Bondo is similar to other previously reported rates for school age children living in holoendemic areas (Table 3 ). While the age range and methods of case detection differ between studies, the empirical estimates are surprisingly consistent. In the majority of studies undertaken in areas with intense, perennial transmission, the annual malaria incidence was typically about $20-25$ cases/100 children per year. Two studies observed higher incidence rates. We could not identify any substantive methodologic difference between these and the other studies, although some variation in point estimates can be expected as a result of the inter-annual and seasonal fluctuations that typify malaria transmission. In comparison, in all areas of low endemicity, the annual incidence of clinical attacks exceeded 34 cases $/ 100$ children per year. In unstable areas, this can rise to 82 cases/100 child-years during an epidemic (as recorded in our study). Although the case definitions used did not always exclude children with low-density parasitemias (whose symptoms can be attributed to malaria with less certainty), it seems reasonable to conclude that school age children living in areas of low transmission experience as many, if not more, clinical attacks per year than children who are exposed to intense perennial transmission.

A single estimate for Nandi masks substantial spatial heterogeneity within the area. Altitude is a well-recognized parameter in delimiting where malaria transmission can occur, and was associated with a five-fold decrease in malaria incidence between an elevation $<1,750$ meters and one $\geq 1,850$ meters. Multivariate analysis including other environmental, household and individual-level factors confirmed altitude of child's home to be the most important risk factor in our highland study population. ${ }^{11}$ Spatial heterogeneity was also observed in Dakar, Senegal, where malaria incidence ranged from 27 to 109 per 100 school children per year according to distance of the child's home from mosquito breeding sites. ${ }^{20}$ Similar micro-variation over short distances has also been reported in other low-transmission settings. ${ }^{21,22}$

In summary, the data reported here, taken together with other published studies, indicate that the risk of malaria morbidity among school age children increases as transmission intensity decreases. The higher malaria burden seen among school children in low-transmission settings presumably reflects host differences in prior exposure and delayed acquisition of immunity. Within populations with little or no ac- 
TABLE 3

Incidence rates of slide-confirmed clinical attacks of malaria among school age children in relation to transmission intensity*

\begin{tabular}{|c|c|c|c|c|c|c|c|c|}
\hline Transmission setting & EIR & Location & $\begin{array}{l}\text { Method of } \\
\text { surveillance }\end{array}$ & $\begin{array}{c}\text { Age } \\
\text { range } \\
\text { (years) }\end{array}$ & $\begin{array}{l}\text { No. of } \\
\text { children }\end{array}$ & $\begin{array}{l}\text { Period of } \\
\text { observation }\end{array}$ & $\begin{array}{l}\text { Observed } \\
\text { incidence/ } \\
100 / \text { month }\end{array}$ & $\begin{array}{c}\text { Malaria } \\
\text { incidence/ } \\
100 \text { per year }\end{array}$ \\
\hline $\begin{array}{l}\text { Stable } \\
\quad \text { Holoendemic }\end{array}$ & Up to 300 & $\begin{array}{l}\text { Asembo Bay, } \\
\text { West Kenya }^{12}\end{array}$ & $\begin{array}{l}\text { ACD every } \\
\text { two weeks }\end{array}$ & $10-14$ & 262 & 2 years & 1.816 & 21.79 \\
\hline \multirow{6}{*}{$\begin{array}{l}\text { All areas of perennial } \\
\text { transmission }\end{array}$} & Up to 300 & Bondo, West Kenya & ACD daily & $8-17$ & 716 & 11 weeks & 2.135 & 25.57 \\
\hline & Up to 250 & Congo $^{29}$ & ACD daily & $11-13$ & 48 & 10 days (peak) & 6.25 & - \\
\hline & & & ACD weekly & $11-13$ & 53 & 17 weeks & 3.661 & 47.60 \\
\hline & $100-200$ & Dielmo, Senegal $^{30}$ & ACD daily & $11-14$ & 14 & 4 months & 1.786 & 21.43 \\
\hline & 100 & Gabon $^{31}$ & ACD daily & $7-17$ & 228 & 9 months & 4.142 & 49.71 \\
\hline & 100 & Cameroon $^{11}$ & ACD daily & $7-17$ & 186 & 6 months & 2.150 & 25.81 \\
\hline ibid & $50-75$ & The Gambia ${ }^{32}$ & ACD weekly & 9-11 & 20 & 7 months & - & 35 \\
\hline $\begin{array}{l}\text { Low-to-moderate } \\
\text { seasonal }\end{array}$ & NA & Ghana $^{33}$ & $\begin{array}{l}\text { Repeated } \\
\text { surveys } \dagger\end{array}$ & $12-20$ & 248 & 4 months & 5.040 & $40.32-60.48 \ddagger$ \\
\hline Low (urban) & $<1$ & Dakar, Senegal $^{20}$ & ACD daily $\dagger$ & $7-11$ & 397 & 15 days & 5.643 & $33.86 \ddagger$ \\
\hline \multirow[t]{2}{*}{$\begin{array}{l}\text { Unstable } \\
\text { Epidemic-prone } \\
\text { highlands }\end{array}$} & NA & $\begin{array}{l}\text { Nandi, Kenya } \\
\text { (range among } \\
\text { schools) }\end{array}$ & ACD daily & $7-20$ & 523 & 11 weeks & $\begin{array}{c}12.810 \\
(5.49-20.44)\end{array}$ & $\begin{array}{c}51.24 \ddagger \\
(21.96-81.74) \ddagger\end{array}$ \\
\hline & NA & Madagascar $^{34}$ & $\begin{array}{l}\text { Outpatient } \\
\text { screening } \dagger\end{array}$ & $10-14$ & 445 & 6 months & 5.84 & 35.06 \\
\hline
\end{tabular}

quired immunity, infection is more likely to result in symptomatic illness, and incidence rates are positively associated with an increased probability of exposure.

In stable transmission areas, where clinical attacks are mild and infrequent, the impact of malaria among semi-immune school children is primarily indirect. Anemia resulting from persistent parasitemia may affect concentration and performance, although the impact is thought to be minimal compared with iron-deficiency anemia. ${ }^{2}$ In contrast, in areas of low or unstable transmission, malaria exerts direct, as well as indirect, effects. Among school children with little immunity, Plasmodium infections are more likely to result in symptomatic illness and, as our data indicate, clinical attacks are also associated with more anemia. Having used a system of active case detection and treatment, we were unable to investigate other aspects of malaria among school children, such as absenteeism, the incidence of severe malaria, or access to treatment under normal circumstances. Other studies suggest that malaria can account for up to $8 \%$ of school absenteeism, ${ }^{23}$ while in areas of low and unstable transmission epidemics can dramatically affect school attendance. ${ }^{15}$ Cerebral malaria is a more common complication in older children, ${ }^{24,25}$ and may be of particular concern among non-immune school children who remain vulnerable to clinical attacks of malaria at older ages. Cerebral malaria is associated with a high case-fatality rate, and it is estimated that $5-20 \%$ of those who survive will have gross neurologic sequelae. ${ }^{2}$ Whether the impact in older individuals at a later stage of neurologic development is similar is unclear. Few studies have documented the burden of malaria in older children and adults, ${ }^{26}$ and the incidence and long-term sequelae of cerebral complications among older age groups particularly warrants study.

Through impaired schooling and educational attainment, malaria ultimately impacts on human capital and economic development of populations living in malarious areas. ${ }^{27}$ Schools offer a potential delivery mechanism for interventions to improve prompt and effective treatment of malaria. $^{4,28}$ A variety of approaches may be possible. First, teachers and pupils need to be equipped with accurate knowledge of appropriate treatment practices through educational materials and training that aim at improving recognition of symptoms and treatment practices, as well as disease prevention and health promotion. ${ }^{19}$ The provision of active control measures in schools, such as intermittent preventive treatment or engaging teachers in routine diagnosis and treatment of pupils can also potentially lessen the impact of malaria. Improving diagnosis and treatment is particularly important in areas of low and unstable transmission where the incidence of clinical attacks in school children is greatest. During epidemics, teachers can also be trained to serve as drug distributors for all age groups in the community (Abeku T, unpublished data). In holoendemic areas, strategies such as intermittent preventive treatment to lessen malaria-associated anemia, integrated into broader school health programs, may be most appropriate.

Received February 14, 2004. Accepted for publication July 7, 2004.

Acknowledgments: We are very grateful to the children and teachers of the schools in Kapkangani and Bondo who kindly participated in the study. We are also most appreciative of those who were responsible for carrying out the active and passive case detection, which made this analysis possible, and the fieldworkers who contributed towards data collection. We are grateful for the excellent work of the late Benbolt Mugo. We also thank Larry Barat, Tarekegn Abeku, and Brian Greenwood for their contributions and suggestions.

Financial support: This work was supported by the Danish Bilharziasis Laboratory, the World Bank, the Bill and Melinda Gates Foundation (through an award to the Gates Malaria Partnership, London School of Hygiene and Tropical Medicine), and the Wellcome Trust (through a Prize Fellowship [062692] to Simon Brooker at the time of the study).

Authors' addresses: Siân E. Clarke and Simon Brooker, Department of Infectious and Tropical Diseases, London School of Hygiene and Tropical Medicine, Keppel Street, London WC1E 7HT, United Kingdom, E-mails: sian.clarke@lshtm.ac.uk and simon.brooker@ lshtm.ac.uk. Joseph Kiambo Njagi, Division of Malaria Control, and Division of Vector Borne Disease, Ministry of Health, Nairobi, Kenya, E-mail: eanmat@africaonline.co.ke. Eliud Njau and Eric 
Muchiri, Division of Vector Borne Disease, Ministry of Health, Nairobi, Kenya, E-mail: dvbd@wanachi.co.ke. Benson Estambale, Kenyatta National Hospital, PO Box 20723, Nairobi, Kenya, E-mail: bestambale@uonbi.ac.ke. Pascal Magnussen, Danish Bilharziasis Laboratory, Charlottenlund, Denmark, E-mail: pm@bilharziasis.dk.

\section{REFERENCES}

1. Snow R, Marsh K, 2002. The consequences of reducing transmission of Plasmodium falciparum infection in Africa. Adv Parasitol 52: 235-264.

2. Holding PA, Snow RW, 2001. Impact of Plasmodium falciparum malaria on performance and learning: review of the evidence. Am J Trop Med Hyg 64 (Suppl): 68-75.

3. Fernando SD, Gunawardena DM, Bandara MR, de Silva D, Carter R, Mendis KM, Wickremasinghe AR, 2003. The impact of repeated malaria attacks on the school performance of children. Am J Trop Med Hyg 69: 582-588.

4. Bundy DAP, Lwin S, Osika JS, McLaughlin J, Pannenborg CO, 2000. What should schools do about malaria? Parasitol Today 16: 181-182.

5. Trape JF, Rogier C, 1996. Combating malaria morbidity and mortality by reducing transmission. Parasitol Today 12: 236-240.

6. Minakawa N, Sonye G, Mogi M, Githeko A, Yan G, 2002. The effects of climatic factors on the distribution and abundance of malaria vectors in Kenya. J Med Entomol 39: 833-841.

7. Beier JC, Oster CN, Onyango FK, Bales JD, Sherwood JA, Perkins PV, Chumo DK, Koech DV, Whitmire RE, Roberts CR, Diggs CL, Hoffman SL, 1994. Plasmodium falciparum incidence relative to entomologic inoculation rates at a site proposed for testing malaria vaccines in western Kenya. Am J Trop Med Hyg 50: 529-536.

8. Malakooti MA, Biomndo K, Shanks GD, 1998. Reemergence of epidemic malaria in the highlands of western Kenya. Emerg Infect Dis 4: 671-676.

9. Hay SI, Were EC, Renshaw M, Noor AM, Ochola SA, Olusanmi I, Alipui N, Snow RW, 2003. Forecasting, warning, and detection of malaria epidemics: a case study. Lancet 361: 1705-1706.

10. World Health Organization, 1983. Measuring Change in Nutritional Status. Geneva: World Health Organization.

11. Brooker S, Clarke SE, Njagi JK, Polack S, Mugo B, Estambale B, Muchiri E, Magnussen P, Cox J, 2004. Spatial clustering of malaria and associated risk factors during an epidemic in a highland area of western Kenya. Trop Med Int Health 9: 757766.

12. Bloland PB, Boriga DA, Ruebush TK, McCormick JB, Roberts JM, Oloo AJ, Hawley W, Lal A, Nahlen B, Campbell CC, 1999. Longitudinal cohort study of the epidemiology of malaria infections in an area of intense malaria transmission. II. Descriptive epidemiology of malaria infection and disease among children. Am J Trop Med Hyg 60: 641-648.

13. World Health Organization, 2001. Iron Deficiency Anaemia: Assessment, Prevention and Control. Geneva: World Health Organization.

14. Smith PG, Morrow RH, eds, 1996. Field Trials of Health Interventions in Developing Countries: A Toolbox. Second edition. Oxford, United Kingdom: Macmillan Education, 306-311.

15. Some ES, 1994. Effects and control of highland malaria epidemic in Uasin Gishu District, Kenya. East Afr Med J 71: 2-8.

16. Hay S, Renshaw M, Ochola SA, Noor AM, Snow RW, 2003. Performance of forecasting, warning and detection of malaria epidemics in the highlands of western Kenya. Trends Parasitol 19: 394-399.

17. Abdalla S, Weatherall DJ, Wickramasinghe SN, Hughes M, 1980. The anaemia of $P$. falciparum malaria. Br J Haematol 46: 171183.
18. Philips RE, Pasvol G, 1992. Anaemia of Plasmodium falciparum malaria. Baillieres Clin Haematol 5: 315-330.

19. Geissler PW, Meinert L, Brooker S, Njagi JK, 2002. School Children, Medicines and Malaria. Findings of the Social Science Component of the Pre-Study on Medicines and Malaria in School-Age Children in a Highland and a Lowland Area of Western Kenya. Report commissioned by the Roll Back Malaria team. Washington, DC: World Bank.

20. Trape JF, Lefebre-Zante E, Legros F, Druilhe P, Rogier C, Bouganali H, Salem G, 1993. Malaria morbidity among children exposed to low seasonal transmission in Dakar, Senegal and its implications for malaria control in tropical Africa. Am J Trop Med Hyg 48: 748-756.

21. Thompson R, Begtrup K, Cuamba N, Dgedge M, Mendis C, Gamage-Mendis A, Enosse S, Barreto J, Sinden RE, Hogh B, 1997. The Matola malaria project: a temporal and spatial study of malaria transmission and disease in a suburban area of Maputo, Mozambique. Am J Trop Med Hyg 57: 550-559.

22. Clarke SE, Bøgh C, Brown RC, Walraven GEL, Thomas CJ, Lindsay SW, 2002. Risk of malaria attacks in Gambian children is greater away from malaria vector breeding sites. Trans $R$ Soc Trop Med Hyg 96: 499-506.

23. Brooker S, Guyatt H, Omumbo J, Shretta R, Drake L, Ouma J, 2000. Situation analysis of malaria in school-aged children in Kenya-what can be done? Parasitol Today 16: 183-186.

24. Imbert P, Sartelet I, Rogier C, Ka S, Baujat G, Candito D, 1997. Severe malaria among children in a low seasonal transmission area, Dakar, Senegal: influence of age on clinical presentation. Trans R Soc Trop Med Hyg 91: 22-24.

25. Snow RW, Omumbo JA, Lowe B, Molyneaux CS, Obiero JO, Palmer A, Weber MW, Pinder M, Nahlen B, Obonyo C, Newbold C, Gupta S, Marsh K, 1997. Relation between severe malaria morbidity in children and level of Plasmodium falciparum transmission in Africa. Lancet 349: 1650-1654.

26. Snow RW, Craig M, Deichmann U, Marsh K, 1999. Estimating mortality, morbidity and disability due to malaria among Africa's non-pregnant population. Bull World Health Organ 77: 624-640.

27. Sachs J, Malaney P, 2002. The economic and social burden of malaria. Nature 415: 680-685.

28. Magnussen P, Ndawi B, Sheshe AK, Byskov J, Mbwana K, 2001. Malaria diagnosis and treatment administered by teachers in primary schools in Tanzania. Trop Med Int Health 6: 1-7.

29. Trape JF, Zoulani A, Quinet MC, 1987. Assessment of the incidence and prevalence of clinical malaria in semi-immune children exposed to intense and perennial transmission. Am J Epidemiol 126: 193-201.

30. Rogier C, Trape JF, 1993. Malaria attacks in children exposed to high transmission: who is protected? Trans $R$ Soc Trop Med Hyg 87: 245-246.

31. Deleron P, Ringwald P, Luty AJ, Renaut A, Minh TG, Mbessy JR, Millet P, 1999. Relationships between malaria prevalence and malaria-related morbidity in school children from two villages in central Africa. Am J Trop Med Hyg 61: 99-102.

32. Marsh K, Hayes RH, Carson DC, Otoo L, Shenton F, Byass P, Zavala F, Greenwood BM, 1988. Anti-sporozoite antibodies and immunity to malaria in a rural Gambian population. Trans $R$ Soc Trop Med Hyg 82: 532-537.

33. Colbourne MJ, 1955. The effect of malaria suppression in a group of Accra school children. Trans R Soc Trop Med Hyg 49: 356369.

34. Lepers JP, Deloron P, Andriamagatiana-Rason MD, Ramanamirija JA, Coulanges P, 1990. Newly transmitted Plasmodium falciparum malaria in the central highland plateaux of Madagasgar: assessment of clinical impact in a rural community. Bull World Health Organ 68: 217-222. 